\title{
The Application of Micro-Plate Dynamics on Monitoring Cell Property
}

\author{
Dr Xianghong Ma and Zhangming Wu \\ School of Engineering and Applied Science, Aston University, Birmingham, B4 7ET, United Kingdom \\ Email: x.ma@aston.ac.uk
}

\begin{abstract}
The paper presents a novel biosensing method of monitoring cell properties using the information derived from the dynamics of micro scale plates. Micro cantilevers have been widely applied as mechanical biosensors. In dynamics sense, cantilever is considered as 1 dimensional whereas plate is a 2 dimensional structure. In this paper we provide the first analytical solution to the dynamics of distributed mass loaded microplate in submerged fluid. In a further step, we propose to derive the dynamical information of the micro plate and use it to infer the spatial information of the cells when monitoring the cell growth on the plate.
\end{abstract}

Index term- micro plate, biosensor, cell property

\section{BACKGROUND}

For future surgery, it is important that surgeons are able to discriminate infected tissue in surgery at the scale of cells, such that micro-surgical procedures can be performed with great accuracy. The solutions will enhance the performance of precision clinical tools, such as micro-surgical robotic devices by examining tissues on a cell by cell basis, or to study cell bio-informatics on the spatial and temporal dimensions. The latter are important growth fields after genomics and proteomics. This paper presents a novel application of Micro plate dynamics for monitoring cell properties.

Using mechanical transducer principles to design biosensing Micro/Nano electromechanical systems is of growing interest for engineers, physicists, chemists and biologists. The most widely applied mechanism is the microcantilever. The merging of micro-fabrication techniques, surface functionalization biochemistry and cantilever sensing methods offers opportunities to develop biosensors for clinical and environmental purposes. Basel et al. [1] propose to detect the presence of receptor-coated magnetic beads that stick to the functionalised surface using microcantilevers. Fritz et al. monitor ssDNA hybridisation with two microcantilevers parallel where their differential deflections allow discrimination of two identical $12 \mathrm{mer}$ oligonucletides with a single base mismatch [2]. The mechanics and dynamics of micro cantilevers have been analysed and understood well due to its wide utilization $[3,4]$.

The dynamics of plates are more complex than cantilevers and pose more interesting dynamical characteristics. Thus plates can provide additional information as a micro sensing medium when compared with cantilevers. Meanwhile, plates offer new benefits for maintaining the natural culture environment of cells (and microbes) due to the fact that viable cells can be maintained on their surfaces in the cell culture medium. It is therefore important to study the dynamics of the micro scale plates in liquid environments.

\section{VIBRATION OF A FLUID-LOADED MICRO PLATE}

This paper presents an analytical method to study the vibration characteristics of the coupled system of a micro scale fluid-loaded rectangular isotropic plate attached with a uniformly distributed mass, which is for simulating the effect of biological cells or particles adhesion to the surface of biosensing plate, based on Lamb's assumption of the fluid-loaded structure and the Rayleigh-Ritz energy method. Numerical results for micro plates with different types of boundary conditions have also been obtained and compared with experimental and numerical results from previous literature. This 
theoretical model will have wide future applications in the design of novel biosensing devices.

The simulated model has been tested and validated by experiments using the Pseudo-Random Binary Sequence (PRBS) excitation and identification method [33]. The advantage of PRBS signals is that they possess the property where their autocorrelation function is a close approximation to the impulse function. The dynamics of all frequencies are excited by PRBS signals. Thus dynamics of the plate under any forcing conditions can be derived.

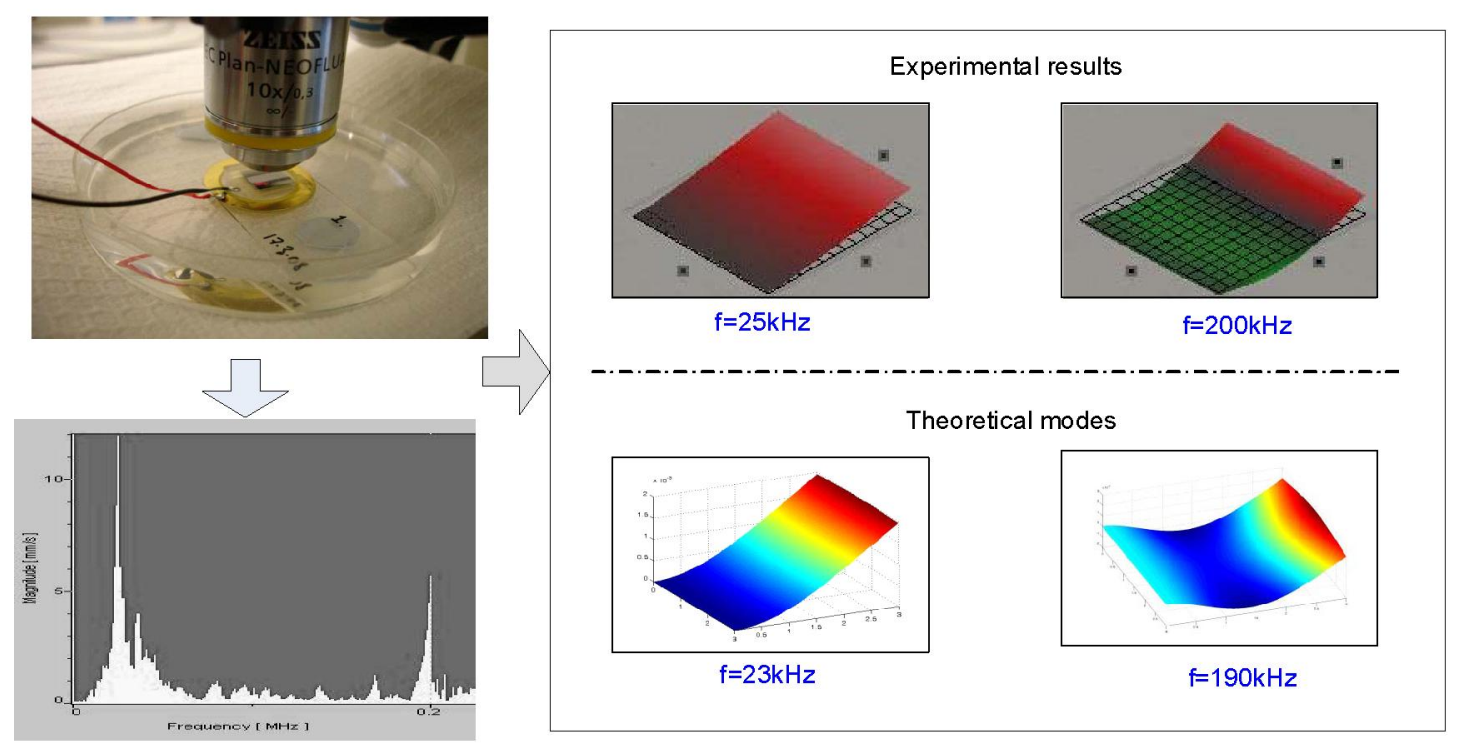

Figure 1. The dynamic characteristics of a micro-plate immersed in liquid subjected to base-excitation by a piezoelectric stage, its dynamic response was experimentally visualized using a laser micro-vibrometer (Polytech MSV400).

\section{APPLICATION TO CELL MONITORING}

Currently cell physical properties and behaviour measurements are mainly performed using microscopy imaging systems. Cell responses to external stimuli are frequently difficult to visualise in real time. To overcome such difficulties and to enable consistent quantitative measurement of cell properties and behaviour, this research proposes to develop an integrated cell monitoring system to detect cell properties and behaviour by using the information derived from the dynamics of a plate submerged in cell culture fluid. Table 1 shows the first 5 Natural Frequency (NF) shifts when cells are growing in a $300 \mu \mathrm{m} \times 300 \mu \mathrm{m}$ plate. Cells are assumed to be a sphere of $10 \mu \mathrm{m}$ with water inside. Figure 2 shows the first 5 mode shapes of the microplate for case 1 when there is no cell on it and case 6 where there are 100 cells adhere to the surface. One can use this dynamics information to deduce the cell properties and behaviour.

Table 1. The first 5 Natural Frequencies of a $300 \mu \mathrm{m} \times 300 \mu \mathrm{m}$ plate when cells are growing on its surface

\begin{tabular}{|l|l|l|l|l|l|}
\hline No of Cells & $1^{\text {st }} \mathrm{NF}(\mathrm{KHz})$ & $2^{\text {nd }} \mathrm{NF}(\mathrm{KHz})$ & $3^{\text {rd }} \mathrm{NF}(\mathrm{KHz})$ & $4^{\text {th }} \mathrm{NF}(\mathrm{KHz})$ & $5^{\text {th }} \mathrm{NF}(\mathrm{KHz})$ \\
\hline 0 & 22.850 & 82.163 & 190.088 & 291.117 & 336.667 \\
\hline 1 & 22.847 & 82.163 & 189.968 & 290.818 & 336.666 \\
\hline 5 & 22.759 & 82.096 & 187.584 & 285.389 & 336.113 \\
\hline 10 & 21.476 & 76.530 & 168.644 & 261.207 & 307.755 \\
\hline 50 & 17.727 & 61.847 & 123.832 & 201.674 & 240.354 \\
\hline 100 & 14.988 & 51.638 & 99.066 & 165.749 & 197.678 \\
\hline
\end{tabular}


case1

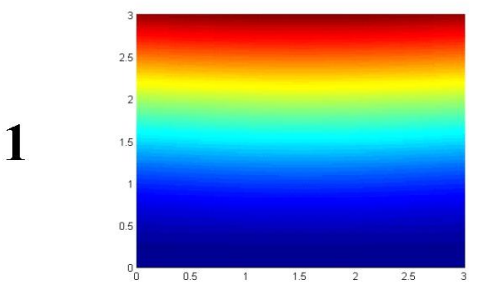

2

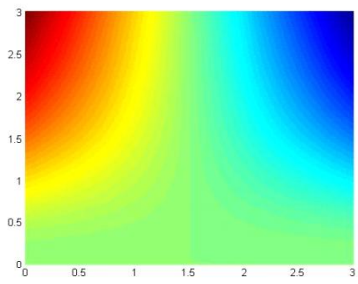

3

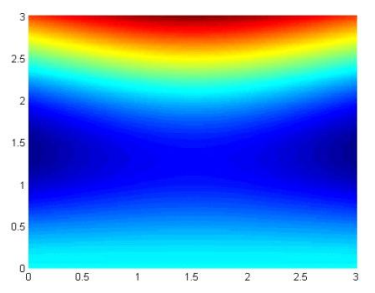

4

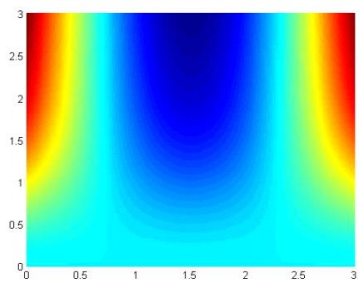

5

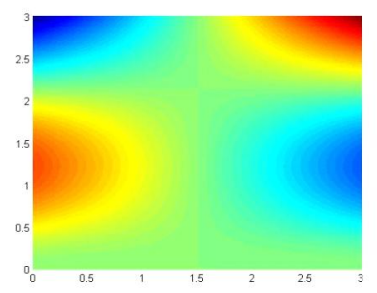

case6
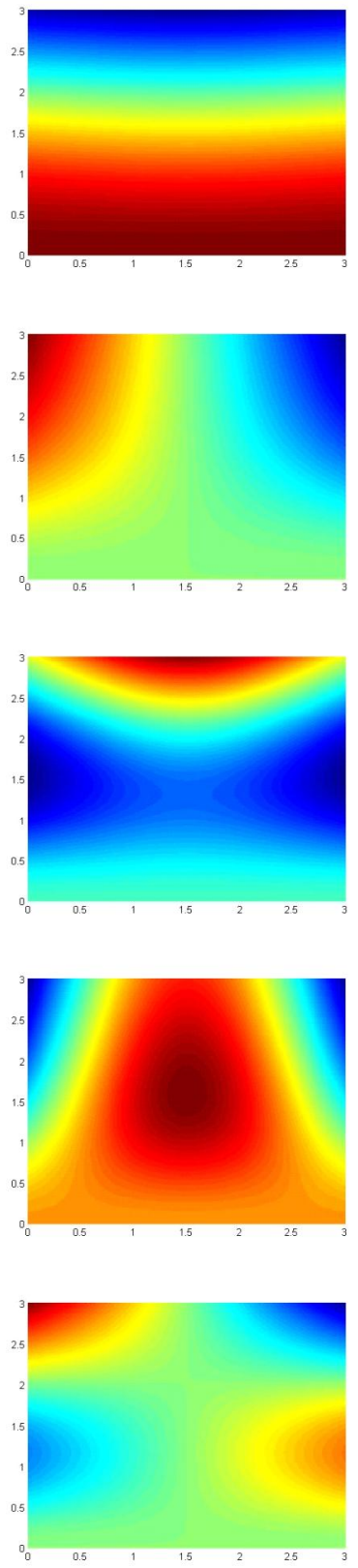

Figure 2. The first 5 mode shapes of the first 5 mode shapes of the microplate for case 1 when there is no cell on it and case 6 where there are 100 cells adhere to the surface

These unique and important results will be investigated with respect to cell morphology, migration, proliferation, differentiation, contractility during cell culture and growth processes. It will have future applications in surgery, clinical pathological diagnosis and pharmacological analysis.

\section{ACKNOWLEDGEMENT}

The research is supported by a grant from the Engineering and Physical Sciences Research Council in the UK.

\section{REFERENCES}

[1] DR Basel, GU Lee, KM Hansen, LA Chrisey and RJ Colton, "A high-sensitivity micromachined biosensor", Biosensors and Bioelectronics, Volume 12, Issue 8, 1997. Page iv. 
[2] Fritz, J; Baller, M K; Lang, H P; Rothuizen, H; Vettiger, P; Meyer, E; Güntherodt, H; Gerber, C; Gimzewski, J K, "Translating biomolecular recognition into nanomechanics" Science, Volume 288, Issue 5464, April 14, 2000, Pages 316-318.

[3] Passian, A. Muralidharan, G.; Mehta, A.; Simpson, H.; Ferrell, T.L.; Thundat, T. , "Manipulation of microcantilever oscillations", Ultramicroscopy, v 97, n 14, October/November, 2003, p 391-399

[4] Lobontiu, Nicolae, Garcia, Ephrahim, "Two microcantilever designs: Lumped-parameter model for static and modal analysis", Journal of

Microelectromechanical Systems, v 13, n 1, February, 2004, p 41-50 